\title{
The impact of high maternal body mass index on obstetric and perinatal outcomes
}

\author{
Natasha Sharma*, Manasi Patnaik \\ Department of Obstetrics and Gynecology, Kalinga Institute of Medical Sciences, Bhubaneswar, Odisha, India
}

Received: 31 December 2020

Accepted: 04 February 2021

\section{*Correspondence:}

Dr. Natasha Sharma,

E-mail: natashasharma91@gmail.com

Copyright: $\odot$ the author(s), publisher and licensee Medip Academy. This is an open-access article distributed under the terms of the Creative Commons Attribution Non-Commercial License, which permits unrestricted non-commercial use, distribution, and reproduction in any medium, provided the original work is properly cited.

\begin{abstract}
Background: The incidence of obesity has increased to pandemic proportions over the last 20 years. Maternal obesity is associated with a wide array of adverse maternal pregnancy outcomes and increased risks in the offspring. The aim of the study was to find the effect of obesity on maternal and perinatal outcome in obese women in comparison to those of normal weight women.

Methods: The study was designed as a case-control study. Antenatal women with first trimester body mass index (BMI) of more than $30 \mathrm{~kg} / \mathrm{m}^{2}$ constituted the cases and those with BMI between 18 and $24.9 \mathrm{~kg} / \mathrm{m}^{2}$ formed the controls.

Results: There was increased incidence of antepartum complications in obese women. Obese women had a significant history of prior treatment for infertility $(\mathrm{p}<0.00001)$. The incidence of gestational diabetes $(\mathrm{OR} 4.76$, 95\% CI 1.267-17.72 p=0.014), gestational hypertension (OR 3.05, 95\%CI 1.01-9.20 p=0.04), induction of labor (OR 2.5, 95\%CI 1.0-6.28 p=0.04), preeclampsia (OR 2.38, 95\%CI 1.0-5.64 p=0.04, Caesarean section (OR 1.98, 95\%CI 1.24-3.14 p=0.003), postpartum haemorrhage (OR 8.57, 95\%CI 1.07-76.15 p=0.04) and wound infection (OR 8.57, 95\% CI 1.07-76.15 $\mathrm{p}=0.04)$ and adverse neonatal outcomes such as higher mean birth weight $(\mathrm{p}<0.0001)$ and requirement of NICU (OR 2.79, 95\%CI $1.33-5.84 \mathrm{p}=0.006$ ) was higher in obese women.

Conclusions: Obesity is an independent risk factor for adverse pregnancy outcomes and hence, interventions directed towards weight loss and prevention of excessive weight gain must begin in the preconception period.
\end{abstract}

Keywords: Body mass index, Maternal outcome, Obesity, Perinatal outcome

\section{INTRODUCTION}

The incidence of obesity has increased to pandemic proportions over the last 20 years. The incidence is higher in females than males according to the World Health Organization (WHO). In 2016, more than 1.9 billion adults, 18 years and older, were overweight. Of these over 650 million were obese. In 2016, 39\% of adults aged 18 years and above were overweight and $13 \%$ were obese. ${ }^{1,2}$ A lifestyle changing towards sedentary has been attributed to increased incidence of obesity in women. According to National Family Health Survey (NFHS)-4 (2015-16), the percentage of women aged 15-49 years who were overweight or obese in India was $20.7 \%$ and in Odisha was $16.5 \% .^{3}$

Body mass index (BMI) is an important predictor of nutritional status of pregnant women which has been considered as an important prognostic indicator of pregnancy outcomes. The BMI is calculated as weight in kilograms divided by the height in meters squared. Categories of BMI are as follows: BMI of $20-24.9 \mathrm{~kg} / \mathrm{m}^{2}$ are considered normal, BMI of $25-29.9 \mathrm{~kg} / \mathrm{m}^{2}$ are overweight, and BMI of $>30 \mathrm{~kg} / \mathrm{m}^{2}$ are obese. ${ }^{4}$ The WHO has defined the criteria of overweight as body mass index (BMI) $>25 \mathrm{~kg} / \mathrm{m}^{2}$ and that for obesity as BMI $>30 \mathrm{~kg} / \mathrm{m}^{2} .^{2}$ 
High maternal body mass index is related to adverse pregnancy outcomes such as preeclampsia, gestational hypertension, pre- and post-term delivery, induction of labor, macrosomia, caesarean section and post-partum haemorrhage. ${ }^{5,6}$

The objective of the study was to find the effect of obesity on maternal and perinatal outcome in obese women compared to those of normal weight women and will highlight the importance of including weight reduction in preconception counseling of obese women.

\section{METHODS}

A prospective case-control study was conducted in the Dept. of Obstetrics and Gynecology, Kalinga Institute of Medical Sciences (KIMS), Bhubaneswar from September 2018 to March 2020.The study population included pregnant women fulfilling our inclusion criteria and willing to participate in our study.

\section{Inclusion criteria}

Women with singleton pregnancy having $\mathrm{BMI} \geq 30 \mathrm{~kg} / \mathrm{m}^{2}$ at first visit, in the first trimester who have not been exposed to other factors already known for causing pregnancy complications other than BMI were considered as cases and those with BMI between 18 and $24.9 \mathrm{~kg} / \mathrm{m}^{2}$ were taken as controls.

\section{Exclusion criteria}

Obese women with medical complications like diabetes, hypertension, hypothyroidism etc. family history, exposure to other factors already known for causing pregnancy complications and those with recurrent abortions where the cause was already known.

All the patients coming for their first antenatal check-up (ANC) in the first trimester were examined after obtaining an informed consent. Their detailed clinical history, physical examination and routine investigations were done. This included complete blood count (CBC), blood grouping, viral marker screening for $\mathrm{HIV}, \mathrm{HbSAg}$ and $\mathrm{HCV}$, serum thyroid stimulating hormone (TSH), urine for routine and microscopic examination and ultrasound scan \{nuchal translucency (NT) scan, nasal bone (NB) scan at 11-13 weeks period of gestation (POG) \}. Subsequent ultrasound scans included Anomaly scan between 18-20 weeks of gestation and fetal growth scan in third trimester. A record of the same was maintained. Weight and height were measured and noted at each ANC. For measuring weight, a standardized bathroom scale was used. For measuring height, stadiometer was used. If they developed any obstetric complications during the course of pregnancy, the necessary investigations were carried out as a part of routine ANC. Glucose challenge test with $75 \mathrm{~g}$ glucose for assessment of GDM was done at first ANC and repeated between 24-28 weeks of pregnancy as mandatory for these patients. Any medical complication developing throughout pregnancy, mode of delivery, any operative interventions, maternal complications and perinatal outcome were noted.

\section{Statistical analysis}

Statistical analysis was performed using Statistics Package for Social Sciences (SPSS) for Windows, version 21.0. The results were assessed at a confidence interval of $95 \%$ and at a significance level of $p<0.05$. A binary logistic regression analysis was carried out to calculate the Odds ratio of different maternal complications. The differences in the variables were evaluated by Chi-square-test for categorical data or by Student t-test for continuous data. The analysis was done separately for each complication so as to independently verify which complication changed due to BMI and which did not.

\section{RESULTS}

A total of 105 pregnant women with $\mathrm{BMI} \geq 30 \mathrm{~kg} / \mathrm{m}^{2}$ (cases) and 150 pregnant women with BMI between 18$24.9 \mathrm{~kg} / \mathrm{m}^{2}$ (controls) were included in the study. Maternal characteristics are presented in Table 1.

Table 1: Maternal characteristics.

\begin{tabular}{|c|c|c|c|}
\hline Characteristics & Obese women (N=105) & Normal weight women ( $N=150)$ & P value \\
\hline Mean age (years) & $26.37 \pm 4.13$ & $26.22 \pm 3.83$ & 0.76 \\
\hline Mean weight at booking (kg) & $81.40 \pm 6.48$ & $53.63 \pm 3.71$ & $<0.0001$ \\
\hline BMI $($ Mean \pm SD, kg/m²) & $31.48 \pm 1.26$ & $20.40 \pm 0.97$ & $<0.0001$ \\
\hline \multicolumn{4}{|l|}{ Parity status N (\%) } \\
\hline Nulliparous & $38(36.19)$ & $67(44.67)$ & \multirow{2}{*}{$\begin{array}{l}0.22 \\
\chi 2=1.499\end{array}$} \\
\hline Multiparous & $67(63.81)$ & $83(55.33)$ & \\
\hline Infertility N (\%) & $21(20)$ & $4(2.67)$ & $<0.00001$ \\
\hline
\end{tabular}

Prior treatment for infertility was higher in obese mothers $(20 \%)$ than in normal weight mothers $(2.67 \%)$ $(\mathrm{p}<0.00001)$. There was no difference observed for gestational age at delivery in both groups $(\mathrm{p}=0.34)$ (Figure 1). 


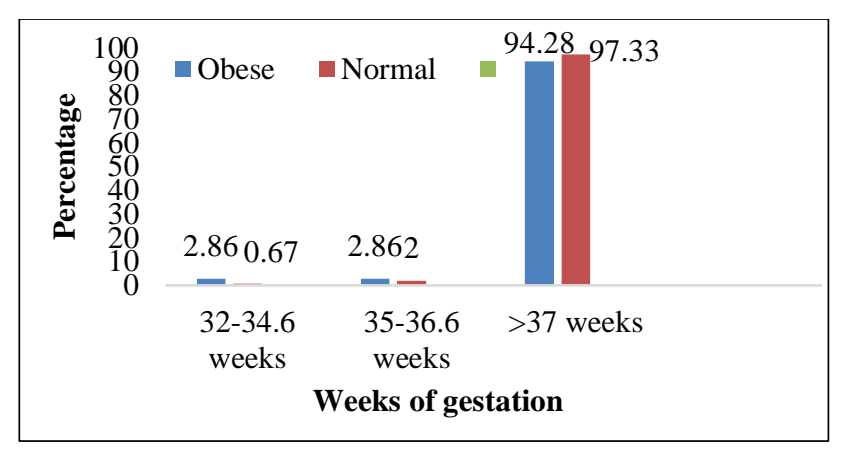

Figure 1: Gestational age at termination.
Obese mothers had 4.76 times more likelihood of developing gestational diabetes mellitus than normal weight mothers. Requirement for induction of labor was also more in obese mothers (Table 2). Gestational hypertension was higher in obese mothers than normal weight mothers $(\mathrm{OR}=3.05)$ and so was preeclampsia $(\mathrm{OR}=2.38)$ (Table 2).

Peripartum complications are summarized in Table 3. Postpartum haemorrhage and wound infection were higher in the obese group $(\mathrm{OR}=8.57$; $=0.04)$.

Table 2: Maternal outcomes.

\begin{tabular}{|c|c|c|c|c|}
\hline Outcome & $\begin{array}{l}\text { Cases N (\%) } \\
\text { obese N }(\%) \\
105\end{array}$ & $\begin{array}{l}\text { Control } N(\%) \\
\text { normal } N=150\end{array}$ & $\begin{array}{l}\text { Odds ratio }(95 \% \\
\text { CI) }\end{array}$ & $P$ value \\
\hline GDM & $10(9.52)$ & $3(2)$ & $4.76(1.27-17.72)$ & 0.014 \\
\hline Induced labour & $13(12.38)$ & $8(5.33)$ & $2.50(1.0-6.28)$ & 0.04 \\
\hline Pre-eclampsia & $15(14.29)$ & $9(6)$ & $2.38(1.0-5.64)$ & 0.04 \\
\hline Gestational hypertension & $10(9.52)$ & $5(3.33)$ & $3.05(1.01-9.20)$ & 0.047 \\
\hline Hypothyroidism & $1(0.95)$ & $1(0.67)$ & $1.43(0.08-23.16)$ & 0.80 \\
\hline PROM & $2(1.90)$ & $1(0.67)$ & $2.89(0.25-32.32)$ & 0.388 \\
\hline Malpresentation & $6(5.72)$ & $6(4)$ & $1.45(0.45-4.64)$ & 0.526 \\
\hline IUGR & $6(5.72)$ & $5(3.33)$ & $1.75(0.52-5.91)$ & 0.362 \\
\hline \multicolumn{5}{|l|}{ Mode of delivery } \\
\hline Caesarean section & $61(58.1)$ & $46(30.67)$ & $1.98(1.24-3.14)$ & 0.003 \\
\hline Normal vaginal & $44(41.9)$ & $104(69.33)$ & & \\
\hline
\end{tabular}

Table 3: Peripartum outcomes.

\begin{tabular}{|lllll|}
\hline Outcome & Obese N(\%) $\mathbf{1 0 5}$ & Normal N (\%) 150 & Odds ratio (95\% CI) & P value \\
\hline PPH & $6(5.71)$ & $1(0.67)$ & $8.57(1.07-76.15)$ & 0.04 \\
\hline Wound infection/gaping & $6(5.71)$ & $1(0.67)$ & $8.57(1.07-76.15)$ & 0.04 \\
\hline
\end{tabular}

Table 4: Neonatal outcomes.

\begin{tabular}{|lllll|}
\hline Outcome & Obese N=105 & Normal N=150 & Odds ratio (95\% CI) & P value \\
\hline Mean weight (kg) & $3.250 \pm 0.534$ & $2.977 \pm 0.421$ & & $<0.0001$ \\
\hline Live born (N, \%) & $100(95.25)$ & $148(98.66)$ & $0.27(0.05-1.42)$ & 0.12 \\
\hline Still born (N, \%) & $3(2.85)$ & $1(0.67)$ & $4.38(0.44-42.72)$ & 0.20 \\
\hline IUD (N, \%) & $2(1.90)$ & $1(0.67)$ & $2.89(0.25-32.32)$ & 0.38 \\
\hline $\begin{array}{l}\text { APGAR score <7 AT 5 } \\
\text { min (N, \%) }\end{array}$ & $3(2.85)$ & $3(2)$ & $1.44(0.28-7.28)$ & 0.65 \\
\hline NICU admission (N, \%) & $22(20.95)$ & $13(8.67)$ & $2.79(1.33-5.84)$ & 0.006 \\
\hline
\end{tabular}

Neonatal outcomes are summarized in Table 4. Neonates born to obese mothers had higher birth weight in comparison to neonates of normal weight women $(\mathrm{p}<0.0001)$. Intrauterine death, still born and low APGAR score ( $<7$ at 5 minutes) were slightly higher in obese group but results were not statistically significant $(\mathrm{p}=0.38,0.2$ and 0.65 respectively). Requirement of neonatal intensive care due to macrosomia and respiratory distress was significantly higher for neonates of obese mothers $(\mathrm{OR}=2.79 ; \mathrm{p}=0.006)$.

\section{DISCUSSION}

The mean weight and BMI at booking for obese women in our study was $81.40( \pm 6.48) \mathrm{kg}$ and $31.48( \pm 1.26) \mathrm{kg} / \mathrm{m}^{2}$ which was statistically significant in comparison with 
normal BMI women $(\mathrm{p}<0.0001)$. The study by Alves et al done in Portugal in 2019 also reported a significant difference in the BMI at booking $(\mathrm{p}<0.001)$ of obese and normal weight women. ${ }^{7}$

In our study, $20 \%$ of obese women required in-vitro fertilization for conception in comparison to only $2.67 \%$ of normal BMI women ( $\mathrm{RR}=7.5$, 95\%CI 2.65-21.21) which was statistically significant $(\mathrm{p}=0.0001)$. Similar results have been reported by previous studies by Vellanki et al, Green et al, Rich-Edwards et al and Grodstein et al. ${ }^{8-11}$ This is attributed to increased insulin resistance, amenorrhea and ovulatory dysfunction in obese women.

Obese pregnant women have been shown to have very high likelihood, two to eleven-fold, of developing gestational diabetes mellitus (GDM) as shown in previous literature by Ovesen et al, Chu et at and Yogev et al. ${ }^{12-14}$ In our study population, obese group developed gestational diabetes mellitus $(9.52 \%)$ in comparison to normal BMI group (2\%). Thus, there was 4.76 fold risk increase for GDM among obese women.

Obese women were observed to have an increased risk of gestational hypertension among by 3.05 folds and preeclampsia by 2.38 folds. This is similar to previous studies. Leddy et al and Dave et al reported an Odds ratio of 2.5 (95\%CI 2.1-3.0) and 2.0 (95\% CI 1.15-3.45) respectively for gestational hypertension in obese women and 3.2 (95\% CI $1.8-5.8$ ) and 2.0 (95\% CI $0.99-4.0)$ respectively for risk of preeclampsia in obese. ${ }^{15,16}$ Obesity in pregnancy leads to increased need for induced labor as well as increased occurrence of failed induction. Labor induction was more common in obese group (12.38\%) when compared to control group (5.33\%). The risk of induction among the obese women in our study was increased almost 2.5 fold (95\%CI 0.92-5.79). This is in accordance with other studies that estimated increase to be between 1.7-fold and 2.2-fold. Kumari et al and Sujatha et al have reported higher rates of labor induction in obese women $(\mathrm{OR}=1.71 ; 95 \% \mathrm{CI} \quad 0.78-3.73$ and $\mathrm{OR}=3.14 ; 95 \% \mathrm{CI} 1.60-5.80$ respectively). ${ }^{17,8}$ The higher early induction rates may be due to the co-morbid conditions that are associated with obesity such as gestational hypertension and preeclampsia.

Obese women had 1.98 fold increased risk (95\% CI 1.243.14 ) of cesarean delivery when compared to control group. It is likely multifactorial with increased dystocia, macrosomia and other maternal complication such as eclampsia or gestational hypertension and diabetes mellitus. Similarly, higher occurrence of need for caesarian section had been reported in previous reports by Scott-Pillai et al, Ramoniene et al, Wahabi et al and Sebire et al. ${ }^{18-21}$ ranging from 1.2 to 2.8 times more in obesity than normal weight mothers.

Higher incidence of PPH was reported in obese group $(\mathrm{OR}=8.57 ; 95 \% \mathrm{CI} 1.01-72.24 ; \mathrm{p}=0.04)$ which was more in comparison with previous studies by Vellanki et al and Kumari et al. ${ }^{8,17}$

Obese women were found to be at a greater risk of postoperative wound infection and gaping $(\mathrm{OR}=8.57 ; 95 \%$ $\mathrm{CI}=1.01-72.24)$.

In our study, the mean birth weight of the neonates of obese group was $3.25( \pm 0.534) \mathrm{kg}$ which was significantly higher $(\mathrm{p}=0.001)$ than the neonates of control group where it was $2.97( \pm 0.421) \mathrm{kg}$. Neonates of obese mothers had increased NICU admission, the major reasons for admission being infants of diabetic mothers and macrosomia. The results are concurrent with previous studies by Usha et al and Vasudevan et al. ${ }^{22,23}$

\section{CONCLUSION}

Obesity during pregnancy carries high maternal and fetal risks. Antenatal complications like GDM, gestational hypertension, preeclampsia, increase in the need for induction of labor and increased incidence of operative interference was associated with pregnancies complicated with obesity. Increased birth weight, stillbirth and higher NICU admissions was also found. Postpartum pregnancy complications like wound infection with increased requirement for secondary suturing was also reported in obese pregnant women. Like all modifiable risk factors of disease, the best approach to obesity in pregnancy is its prevention. Approaches to prevent complications of obesity in pregnancy can be offered in pre-pregnancy period. During pregnancy excessive weight gain is also to be avoided. Education and awareness is essential for all women of child bearing age regarding the risk of adverse outcome associated with obesity in pregnancy. Pregnancy in obese mothers should be considered as a high risk condition and warrants a high level specialized antenatal, natal and post-natal care.

\section{Funding: No funding sources}

Conflict of interest: None declared

Ethical approval: The study was approved by the Institutional Ethics Committee

\section{REFERENCES}

1. Flier JS, Maratos-Flier E. Biology of Obesity. In: Fauci, Braunwald, Kasper, Hauser, Longo, Jameson, Loscalzo. Harrison's Principles of Internal Medicine. 17th ed. New York: McGraw-Hill;2008:463.

2. WHO. Obesity and overweight, 2020. Available from: https://www.who.int/news-room/factsheets/detail/obesity-and-overweight. Accessed at 28 December 2020.

3. National Family Health Survey-4: 2015-16. Ministry of Health and Family Welfare, Government of India. Available at: http://rchiips.org/nfhs/NFHS4Reports/India.pdf. Accessed at 28 December 2020. 
4. Cunningham FG, Leveno KJ, Bloom SL, Hauth JC, Rouse DJ, Spong CY. Williams Obstetrics. 23rd ed. McGraw-Hill;2010:946.

5. Rowlands I, Graves N, de Jersey S, McIntyre HD, Callaway L. Obesity in pregnancy: outcomes and economics. Semin Fetal Neonatal Med. 2010;15(2):94-9.

6. Dennedy MC, Dune F. The maternal and fetal impacts of obesity and gestational diabetes on pregnancy outcome. Best Pract Res Clin Endocrinol Metabol. 2010;24:573-89.

7. Alves P, Malheiro MF, Gomes JC, Ferraz T, Montenegro N. Risks of Maternal Obesity in Pregnancy: A Case-control Study in a Portuguese Obstetrical Population. Rev Bras Ginecol Obstet. 2019;41(12 ):682-7.

8. Vellanki VS, Kocherlakota VL, Kaul R. High body mass index in pregnancy, its effects on maternal and fetal outcome. J Clin Gynecol Obst. 2012;1(1):15-8.

9. Green BB, Weiss NS, Daling JR. Risk of ovulatory infertility in relation to body weight. Fertil Steril. 1988;50:721-6.

10. Rich-Edwards JW, Goldman MB, Willett WC, Hunter DJ, Stampfer MJ, Colditz GA, Manson JE. Adolescent body mass index and infertility caused by ovulatory disorder. Am J Obstet Gynecol. 1994;171:171-7.

11. Grodstein F, Goldman M, Camer DE. Body mass index and ovulatory infertility. Epidemiol. 1994:5:247-50.

12. Ovesen P, Rasmussen S, Kesmodel U. Effect of Prepregnancy Maternal Overweight and Obesity on Pregnancy Outcome. Obstet Gynecol. 2011;118:30512.

13. Chu SY, Callaghan WM, Kim SY, Schmid CH, Lau J, England LJ, et al. Maternal Obesity and Risk of Gestational Diabetes Mellitus. Diabet Care. 2007;30(8):2070-6.

14. Yogev Y, Visser GHA. Obesity, gestational diabetes and pregnancy outcome. Semin Fetal Neonatal Med. 2009;14(2):77-84.
15. Leddy MA, Power ML, Schulkin J. The impact of maternal obesity on maternal and fetal health. Rev Obstet Gynecol. 2008;1(4):170-8.

16. Dave A, Maru L, Daksha S, Natu N. Weight does Matter! A Study of Effect of Obesity on Pregnancy and its Outcome. J SAFOG. 2013;5:107-10.

17. Kumari P, Gupta M, Kahlon P, Malviya S. Association between high maternal body mass index and feto-maternal outcome. J Obes Metab Res. 2014;3:143-4.

18. Scott-Pillai R, Spence D, Cardwell C, Hunter A, Holmes V. The impact of body mass index on maternal and neonatal outcomes: a retrospective study in a UK obstetric population, 2004-2011. BJOG Int J Obstet Gynaecol. 2013;120(8):932-9.

19. Ramonienè G, Maleckienè L, Nadišauskienė RJ, Bartusevičienè E, Railaite DR, Mačiulevičienè R, et al. Maternal obesity and obstetric outcomes in a tertiary referral center. Medicina. 2017;53(2):109-13.

20. Wahabi HA, Fayed AA, Alzeidan RA, Mandil AA. The independent effects of maternal obesity and gestational diabetes on the pregnancy outcomes. BMC Endocrine Disorders. 2014;14(1):47.

21. Sebire NJ, Jolly M, Harris JP, Wadsworth J, Joffe M, Beard RW, et al. Maternal obesity and pregnancy outcome: a study of 287213 pregnancies in London. Int J Obesity. 2001;25(8):1175.

22. Usha Kiran TS, Hemmadi S, Bethel J, Evans J. Outcome of pregnancy in a woman with an increased body mass index. BJOG. 2005;112(6):768-72.

23. Vasudevan C, Renfrew M, McGuire W. Fetal and perinatal consequences of maternal obesity. Arch Dis Child Fetal Neonatal Ed. 2011;96(5):F378-82.

Cite this article as: Sharma N, Patnaik M. The impact of high maternal body mass index on obstetric and perinatal outcomes. Int J Reprod Contracept Obstet Gynecol 2021;10:1031-5. 